\title{
Identifying critical parameters in the settling of African kimberlites
}

\author{
E.T. Boshoff ${ }^{a}$, J. Morkel ${ }^{\text {b }}$ N. Naude ${ }^{b}$ \\ ${ }^{a}$ Kwena Mining Projects, South Africa, theodor.boshoff@gmail.com \\ ${ }^{\mathrm{b}}$ Department of Materials Science and Metallurgical Engineering, University of Pretoria, \\ Lynnwood Drive, Pretoria 0002, South Africa
}

\begin{abstract}
Kimberlite is the host rock of diamonds and varies widely in geological, and mineralogical features as well as colour, processing capability and dewatering characteristics. This study investigated the dewatering behaviour of problematic Angolan kimberlites. The presence of clay minerals in kimberlite causes difficulties in dewatering due to high flocculant demand, poor supernatant clarity and low settling rates. Identifying critical parameters governing the settling behaviour will assist in managing the settling behaviour of different kimberlite slurries. The influence of particle size, $\mathrm{pH}$ of the kimberlite slurry, cation exchange capacity, exchangeable sodium percentage and smectite content of the kimberlite on the settling rate were investigated for 18 different African kimberlite samples. The settling rate and slurry bed compaction during natural settling were also measured for the kimberlite slurries. Seventeen different Angolan clay-rich kimberlites and one South African clay-rich kimberlite were tested and, except for two kimberlites, colloidal stability was experienced during natural settling. The $\mathrm{pH}$ values of the kimberlite slurries ranged between $9-11$, which is similar to the $\mathrm{pH}$ band where colloidal stability was found during earlier research.
\end{abstract}


The results indicate that colloidal stable slurries were experienced with kimberlites that had exchangeable sodium percentages as low as $0.7 \%$. The cation exchange capacity of the various kimberlites differentiated more distinctly between colloidal stability and instability. A new model is proposed whereby clay-rich kimberlites with a cation exchange capacity of more than $10 \mathrm{cmol} / \mathrm{kg}$ will experience colloidal stability if the $\mathrm{pH}$ of the solvent solution is within the prescribed $\mathrm{pH}$ range of $9-11$.

Key words: kimberlite, smectite, exchangeable sodium percentage, cation exchange capacity.

\section{Introduction}

Kimberlite is the host rock from which diamonds are mined. There are to date up to 4000 different kimberlites and lamproites intrusions identified and more are identified each year due to the systematic exploration programme carried out by the various diamond exploration companies. Various attempts have been made to classify kimberlites according

to the different mineralogical compositions. Mitchell (1986) classifies three groups of kimberlites according to the amount of olivine, phlogopite and calcite, kimberlite (equivalent to basaltic kimberlite), micaceous kimberlite (equivalent to lamprophyric kimberlite), and calcite or calcareous kimberlite. Skinner and Clement (1979) classify kimberlites into five groups according to the predominance of diopside, monticellite, phlogopite, calcite and serpentine present. Serpentine is formed over centuries during the alteration process of olivine and is one of the main minerals in blue ground. Blue ground is unweathered kimberlite found deeper in the volcanic pipe. Serpentine can account for 20$50 \%$ of the groundmass in the mineral and chemically breaks down into the clay minerals 
of smectite, vermiculite, calcite, chlorite and talc during the weathering process (Hopwood et al, 1975).

The presence of clay minerals in the kimberlite ore can cause difficulty in dewatering due to high flocculant demand, poor supernatant clarity and low settling rates (e.g. $<0.1 \mathrm{~m} / \mathrm{h})($ McFarlane et al, 2005b). The slurry stream can be divided into two fragments, namely grits and slimes. Grits are defined as the larger particles, $75 \mu \mathrm{m}-1.0$ $\mathrm{mm}$, and slimes are particles smaller than $75 \mu \mathrm{m}$. Grits settle out quickly due to gravitational forces dominating, while the slimes are mostly stable in suspension. Slimes can further be divided into particles that are large enough to settle out given enough time, and the colloidal stable particles. The colloidal stable slimes fraction is predominantly clay minerals and is responsible for most of the settling problems in the diamond industry. O' Gorman and Kitchener (1972) note that these slime particles do not adhere, but rather collide with one another, resulting in a vigorous Brownian motion where particles stay separate in suspension. The word clay is used synonymously with very fine material and often clays are defined as the - $45 \mu \mathrm{m}$ material (Klein \& Hurlbut, 1993). From first principles the settling velocity of small spheres in a fluid, whether it is air or water, is described by Stokes law where:

$$
\omega=\frac{2\left(\rho_{p}-\rho_{f}\right) g r^{2}}{9 \mu}
$$

$\omega=$ settling velocity $(\mathrm{m} / \mathrm{s}), \rho_{\mathrm{p}}=$ particle density, $\rho_{\mathrm{f}}=$ fluid density, $\mathrm{g}=\operatorname{gravity}\left(\mathrm{m} / \mathrm{s}^{2}\right), \mathrm{r}=$ radius of the particle $(\mathrm{m}), \mu=$ dynamic viscosity of fluid 
The expectation is that the smaller the average particle size, the lower the settling velocity of the particles and the more difficult it is to settle the slurry. Identifying critical parameters that can predict the settling behaviour of African kimberlite slurries will assist the process engineer to predict the settling behaviour of different kimberlite slurries. Identifying the kimberlites that will most likely not settle with normal flocculant dosage rates is especially useful. Operations have identified that more weathered material tends to increase problems in settling. Whether it is due to the fine size or mineralogical features is not clear (Vietti \& Dunn, 2003).

The processing plants of the diamond industry tend to be water intensive and require efficient dewatering for reuse of water and for sustainable environmental disposal. Often diamond processing plants have difficulty with dewatering. This project ultimately aims to improve dewatering of kimberlite slimes by identifying the critical parameters that influence settling and dewatering behaviour. The settling behaviour is usually predicted by the particle size of the fine material. However, utilising only particle size is in most cases unsuccessful in predicting settling behaviour. One area that has been identified as a major contributor to settling is the mineralogical feature of the kimberlite and research has shown that different types of clay minerals tend to behave differently during settling (Bland \& Rolls, 1998).

The settling of clay dispersions is dependent on the chemical interactions of the particle with the solution, as well as other particles in solution. The main chemical parameters influencing the settling of the clay particles are the diffuse double layer or zeta potential $(\zeta)$ surrounding the clay particles, the $\mathrm{pH}$ of the solution and the cation exchange between the clay particles and the solution. 
The zeta potential $(\zeta)$ is defined as the electrical potential at the plane of shear of the diffuse electric double layer and is the only experimentally possible measurement of particle charge. The zeta potential is dependent on the surface charge of the particles and on the concentration and charge of the counter-ions in solution, according to Wills (1997). Derjaguin and Landau (1941) and Verwey and Overbeek (1948) used the double layer compression concept to develop the DLVO theory for particle-particle interaction. This theory states that when two particles in solution move closer to one another, the electric double layers will overlap and the residual attraction energy can be predicted by adding the double layer repulsion and van der Waal's attractive energies. In a solution with high ionic strength, the electric double layer will be compressed, resulting in a lowering of the strength of the repulsive forces surrounding the clay particles. This allows particle interaction to occur, which leads to more effective dewatering.

The clay mineral surface charge account for almost $80 \%$ of the exchangeable cation capacity, while the remainder is attributed to the clay particle edges, according to Vietti (2004). Under aqueous conditions, the hydroxyl (OH-) groups will attach to the exposed silicon tetrahedral and metal ion octahedral atoms at the clay edges, as indicated by Svarovsky (1981). An increase in $\mathrm{pH}$ deprotonate the $\mathrm{OH}$ - groups until an edge neutrality is reached. This $\mathrm{pH}$ is defined as the point of zero charge (ZPC), as seen in Figure 1. A further increase in $\mathrm{pH}$ results in the clay edges to be dominated by an overall negative charge because of the deprotonation of the $\mathrm{OH}$ - groups, which result in colloidal stability of the clay particles. 


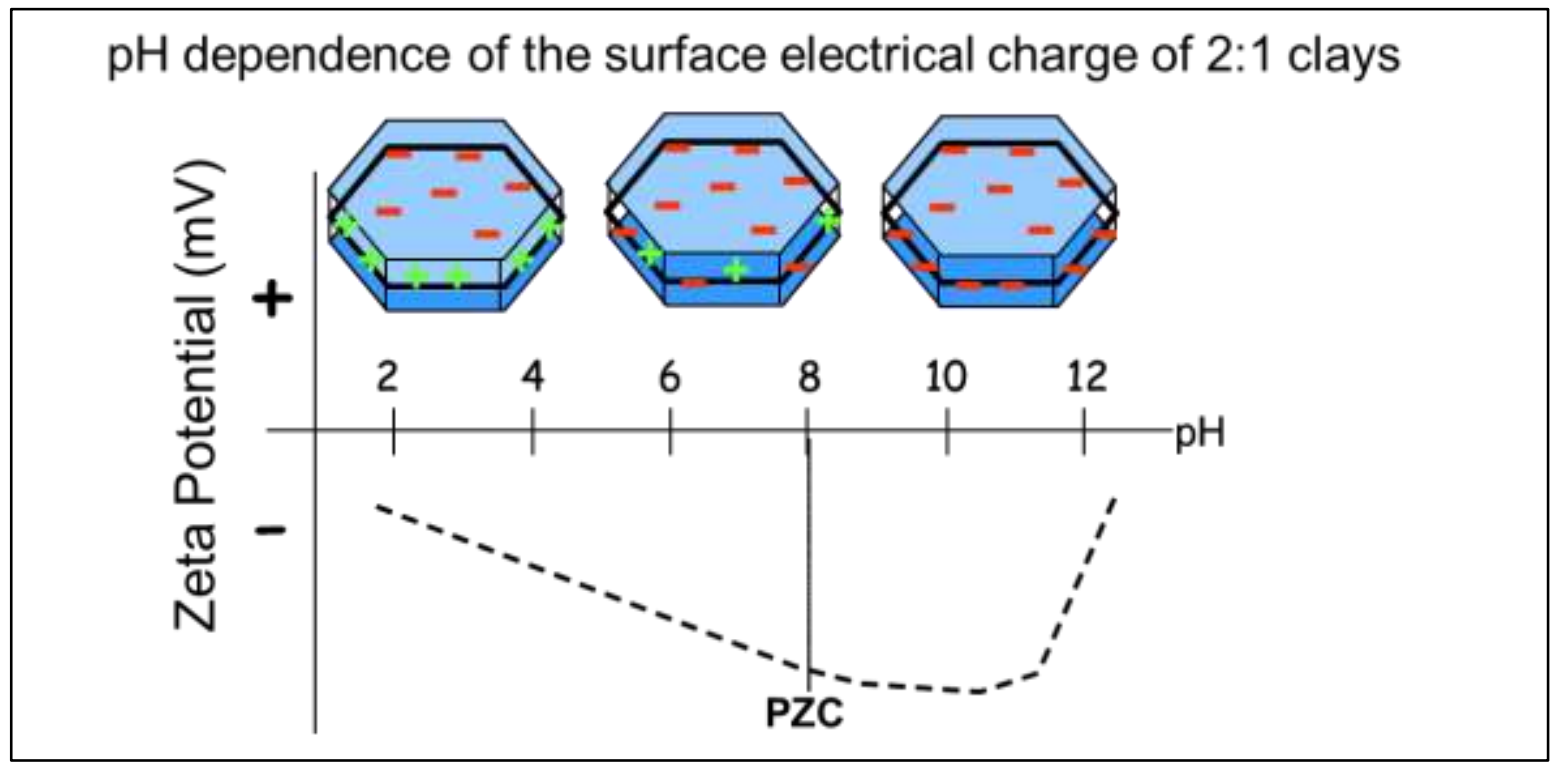

Figure 1: $\mathrm{pH}$ dependence of the surface electrical charge of 2:1 clays according to Vietti (2004)

Settling difficulties are associated with repulsive forces surrounding the colloidal particles at low ionic concentrations. As the ionic concentration increases, the electric double layer surrounding particles contracts and the particles can interact with one another. The ionic concentration at which particles start to attract one another is defined as the critical coagulation concentration (CCC).

The $\mathrm{pH}$ of the dispersion plays an important role, as it dictates which hydrolysed cation species was adsorbed, while agitation could improve the settling by allowing more particle-polymer interaction (McFarlane et al, 2005a) (McFarlane et al, 2005b).

\subsection{Kimberlite clay characteristics}

Clay minerals are categorised as swelling, smectite and vermiculite, and non-swelling clay minerals, kaolinite, based on the linkage between the adjacent sheets. Non-swelling clay minerals have a 1:1 linkage between the tetrahedra sheets, while swelling clay minerals 
have a 2:1 linkage where two tetrahedra sheets are linked to an octahedra sheet. Strong Coulombic forces hold the sheets together, as well as weak Van der Waals forces. Crystalline swelling takes place first when the exchangeable cations are hydrated and widening of the clay structure occur. The second phase of swelling is due to osmotic swelling in the clay mineral. Osmotic swelling occurs because of a large concentration difference between the electro-statically bonded ions on the surface and the pore water of the rock. This results in an excess negative charge on the surface, which must be corrected by positive ions close to the clay crystal surface and a resultant high concentration of positive ions close to the surface. This cloud of positive ions and the negative surface layer form the diffuse electric double layer. The swelling of these clays results in poor settling rates (e.g. $<0.1 \mathrm{~m} / \mathrm{h})$, as well as a low sediment solid loading ( $<10 \mathrm{wt} . \%)$, according to McFarlane et al (2005).

Clay particles can have various particle packing relationships due to the shape of the clay particles and the anisotropic charge. The main two packing relationships are the edgeface ("house-of-cards") and the face-face ("band structure") interactions, as described by McFarlane et al (2005), Verwey and Overbeek (1948), and Lagaly (1993). According to McFarlane et al (2005), smectite particles form "honeycomb" structures which retain large volumes of water in void spaces similar to the "house of cards" structure. It is these large volumes of water that need to be removed for effective dewatering. Clays where swelling have occurred are not normally associated with the "house of cards" structure, because the total edge-face surface area is very small compared to the basal face area. The basal face negative charge is significantly larger than the edge face positive charge and the thin 
particles can bend normally to the interlayer orientation, according to McFarlane et al (2005).

Clay particles are known for cation exchanges that take place to balance out the overall negative charge on the particle edges. The cation exchange capacity (CEC) of an ore is its ability to adsorb cations and is measured as the number of centimoles (cMol) of cations replaced per kilogram of ore treated, as described by Bland and Rolls (1998). This indicates that if an ore has a CEC of $10 \mathrm{Mol} / 100 \mathrm{~g}, 100 \mathrm{~g}$ of ore can exchange $10 \mathrm{Mol}$ of $\mathrm{Na}^{+}$with $10 \mathrm{Mol}$ of another cation. It was found that the CEC for smectite can range from 60-150 mili equivalents per 100-gram due to the high isomorphous substitution and layer charge, according to Lagaly (1993). Mpofu et al (2004) also demonstrate that if the concentration of divalent cations is sufficient to complete cation exchange with $\mathrm{Na}^{+}$ions, the CEC of the clay is reached and this can lead to more effective dewatering.

In agriculture, the exchangeable sodium potential (ESP) of an ore is used to determine whether the groundwater will become alkaline and result in settling difficulties for clay particles. ESP is the percentage that sodium ions contribute to the overall cation exchange capacity of an ore.

Vietti (2004) shows that kimberlite clay slurries, which have a $\mathrm{pH}$ value of between 9 and 11 and have an ESP of more than 15\%, will experience a rapid increase in the slimes colloidal stability. This model is shown in Figure 2. This stability of the colloidal particles can be ascribed to the reduction of the divalent cation constituent in the process water and an increase in the $\mathrm{Na}^{+}$concentration, possibly due to cation exchange taking place in the kimberlite slime particles. 

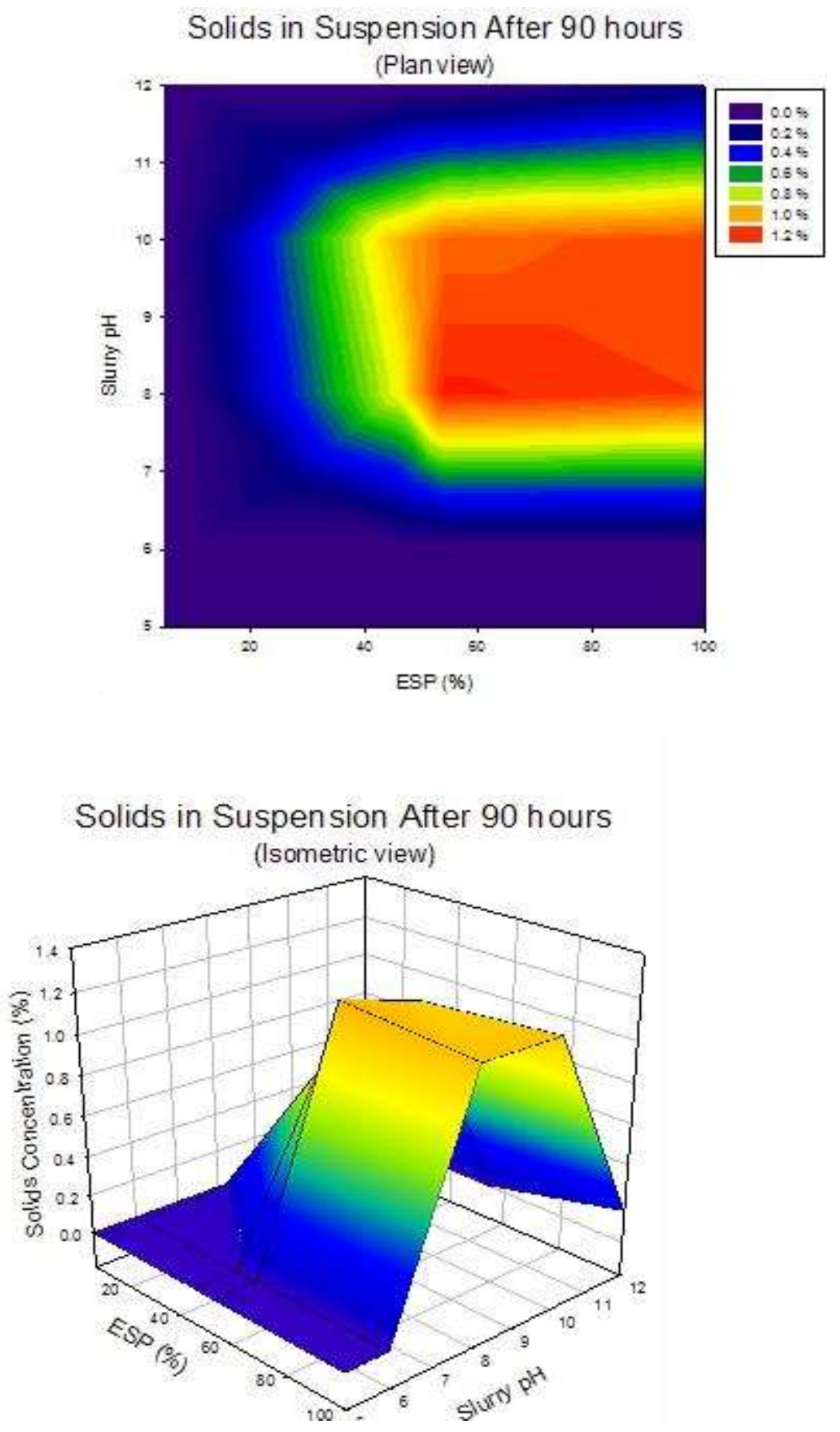

Figure 2: Model for Describing the Suspension Behaviour of Naturally Settling Low-Density Kimberlitic Clay Slurries (Vietti, 2004) 
This project investigated if the ESP and $\mathrm{pH}$ of the slurry are the only critical parameters in predicting the natural settling behaviour for these Angolan kimberlites and whether it could be expanded to flocculant settling as well.

\section{$2 \quad$ Experimental}

\subsection{Material}

Seventeen samples were received from twelve different kimberlite pipes situated in three different kimberlite pipe clusters in Angola, namely Alto Cuilo, Itengo and Tchegi, and compared with a known colloidal stable South African kimberlite, Venetia Red. X-ray diffraction (XRD) analysis was done on the kimberlite samples to determine the mineralogy with specific interest in the percentage smectite contained in each kimberlite. The cation exchange capacity (CEC) for every sample was determined through the ammonium acetate method for soil analyses and is expressed as centimol (+) per kilogram of ore (Chapman, 1965). The exchangeable sodium percentage for each sample was calculated from the results of the cation exchange capacity.

The influence of clay particles on the settling characteristics of kimberlite slimes was tested by milling the drill core samples down to $-75 \mu \mathrm{m}$, whereafter the slimes were made up to a $10 \%$ slurry by mass. The use of drill core samples instead of thickener samples required that the relevance of the data was based on a crushed drill core sample having the same clay mineral composition as the kimberlite ore body at the same depth. The milled drill core sample was magnetically stirred in distilled water for 15 minutes at 
1000 revolutions per minute. An average density of $2.65 \mathrm{~g} / \mathrm{cm}^{3}$ for the kimberlite samples was used to calculate the sediment bed depth.

\subsection{Particle size}

Particle size is usually regarded as the most important variable in particle settling, where especially fine particles will cause very slow settling or colloidally stable suspensions. The most colloidally stable and hence most difficult size ranges to settle in slurries are typically below $75 \mu \mathrm{m}$ (Vietti, 2004). The clay minerals are usually concentrated in this size fraction. Particle size was determined by the low angle laser light scattering (LALLS) analysis that is utilised by the Malvern Mastersizer 2000. The light diffraction of the particle passing through the laser beam is inversely proportional to the particle size.

\subsection{Natural settling}

For natural settling investigations, $50 \mathrm{~g}$ of kimberlite were added to a $450 \mathrm{ml}$ of distilled water and stirred with a magnetic stirrer at a $1000 \mathrm{rpm}$ for 15 minutes. The kimberlite dispersion was left to stand for 15 minutes. For each test $500 \mathrm{~cm}^{3}$ of the kimberlite dispersion was used. The measuring cylinder was inverted three times to ensure a wellmixed dispersion. The initial settling rates were determined by tracking the "mud-line" (solid-liquid interface) in a $500 \mathrm{~cm}^{3}$ measuring cylinder and measuring the distance covered in 30 seconds. The sediment bed depth for each sample was recorded by measuring the volume in millilitre $(\mathrm{ml})$ of the consolidated sediment bed after 24 hours. 


\subsection{Flocculant settling}

Anionic polydiallyldimethyl-ammonium (PAM) was tested, as this is the most commonly used flocculant in the diamond industry. The Magnafloc range from Senmin is commonly used in South Africa's diamond industry where clay problems arise. Fresh flocculant solutions were prepared by mixing a known mass of the flocculant powder with a known volume of distilled water to achieve flocculant strength of $0.025 \%$. The solution was agitated for an hour at $1000 \mathrm{rpm}$ before leaving it for 24 hours to ensure flocculant activation. Flocculant solutions were used within three days to minimise flocculant aging. Kimberlite dispersions of $10 \mathrm{wt}$. \% solid was prepared by mixing $50 \mathrm{~g}$ of each kimberlite with 450ml of distilled water. For flocculant and settling investigations, known volumes of $0.025 \%$ of polymeric flocculant solutions were added in a single step to a $10 \mathrm{wt}$ \% solid kimberlite slurry. For each test $500 \mathrm{~cm}^{3}$ of the kimberlite dispersion was used. The measuring cylinder was inverted three times to ensure a well-mixed dispersion. The initial settling rates were determined by tracking the "mud-line" (solid-liquid interface) in a 500 $\mathrm{cm}^{3}$ measuring cylinder and measuring the distance covered in 30 seconds. The sediment bed depth for each sample was recorded by measuring the volume in millilitre (ml) of the consolidated sediment bed after 24 hours. The weight percentage solids in the sediment bed was calculated.

\subsection{Regression modelling}

An online software package, Business Spreadsheets' Multiple Regression Analysis and Forecasting, was used for regression modelling of the flocculant-assisted settling of the 
kimberlite slurries. No regression modelling was possible with regard to natural settling, as settling did not take place. Smectite percentage, cation exchange capacity (CEC), exchangeable sodium percentage (ESP), particle size and $\mathrm{pH}$ of the kimberlite slurries were used as independent variables, while the flocculant settling rate and sediment bed depth of the kimberlite slurries were used as dependent variables. For representation of the particle size, two data points from the particle size distribution were utilised, representing the fine material and the coarser material. These two data points were taken at $7.5 \mu \mathrm{m}$ and $75 \mu \mathrm{m}$. The clay minerals are predominantly found in the $-7.5 \mu \mathrm{m}$ fraction of kimberlite slurries and $-75 \mu \mathrm{m}$ fraction represent the most difficult particles to settle, according to Vietti (2004). The independent variables were normalised by dividing the values by 100 , and the

$\mathrm{pH}$ was normalised by dividing the $\mathrm{pH}$ values by 14 . The regression model was evaluated in terms of its standard error, $\sigma$, and $\mathrm{R}^{2}$ adjusted whereafter the significance of the model was determined by the significance of $\mathrm{F}$ through the analysis of variance. The coefficients were evaluated on its respective P-values, where a P-value smaller than 0.05 was significant, based on a 95\% confidence level. Coefficients with values larger than 0.05 were insignificant and the regression was run again with the remaining variables. This process was repeated until a significant model was found with significant coefficients.

\section{$3 \quad$ Results and discussion}

\section{$3.1 \quad$ Mineral composition}

The XRD analyses were done to determine the percentage of smectite for each kimberlite, to investigate the influence of these swelling clay minerals on the settling behaviour of the 
kimberlite dispersions as well as the resultant sediment bed compaction. Table 1 shows the smectite percentage for the different kimberlites, where the smectite percentage varies from $15 \%$ to $75 \%$, the cation exchange capacity (CEC) varies from 5 to $77 \mathrm{cmol}(+) / \mathrm{kg}$ between the kimberlites and the exchangeable sodium percentage (ESP) varies from $1 \%$ to $43 \%$. The $\mathrm{pH}$ values of the kimberlite slurries vary between 9.3 and 10.6.

Table 1: Percentage smectite, cation exchange capacity, exchangeable sodium percentage of the kimberlite samples and the $\mathrm{pH}$ of the kimberlite slurries.

\begin{tabular}{|c|c|c|c|c|c|}
\hline Sample name & Kimberlite number & Smectite \% & CEC & ESP \% & pH \\
\hline AC-1-1-1 & 1 & 50 & 5 & 2 & 9.3 \\
\hline AC-5-5-1 & 2 & 50 & 10 & 3 & 9.3 \\
\hline AC-4-1A-1 & 3 & 75 & 45 & 1 & 9.5 \\
\hline AC-5-5-2 & 4 & 70 & 48 & 1 & 9.5 \\
\hline AC-16-11-1 & 5 & 70 & 31 & 6 & 9.7 \\
\hline AC-56-5-1 & 6 & 65 & 54 & 30 & 10.6 \\
\hline AC-197-1-1 & 7 & 40 & 19 & 17 & 10.1 \\
\hline A0319 & 8 & 60 & 67 & 21 & 9.4 \\
\hline A0320 & 8 & 60 & 59 & 3 & 9.7 \\
\hline A0321 & 9 & 35 & 68 & 5 & 9.9 \\
\hline A0322 & 9 & 60 & 31 & 2 & 9.7 \\
\hline AO323 & 9 & 15 & 13 & 1 & 9.3 \\
\hline A0324 & 10 & 55 & 56 & 17 & 10.3 \\
\hline A0325 & 10 & 30 & 22 & 2 & 9.8 \\
\hline A0326 & 11 & 55 & 53 & 3 & 9.8 \\
\hline AO327 & 12 & 25 & 18 & 8 & 10.0 \\
\hline AO328 & 12 & 60 & 77 & 21 & 10.1 \\
\hline Venetia Red & 13 & 40 & 32 & 43 & 10.6 \\
\hline & & & & & \\
\hline
\end{tabular}

\subsection{Particle size}

Settling behaviour is usually predicted from a theoretical point of view by the particle size distribution and Stokes law for single particles. It is usually assumed that a finer particle size distribution of the kimberlite slurry will be more difficult to settle. 
Figure 3 shows the particle size analyses of the Alto Cuilo samples. Sample particles size distributions range between $20 \%$ and $40 \%$ passing $7.5 \mu \mathrm{m}$, and $60 \%$ and $80 \%$ passing $75 \mu \mathrm{m}$. This could be indicative of harder kimberlite mineralogy. A coarser size range in a sample could lead to a higher settling rate due to an increased influence of gravity on the settling of the particles in the kimberlite slurries.

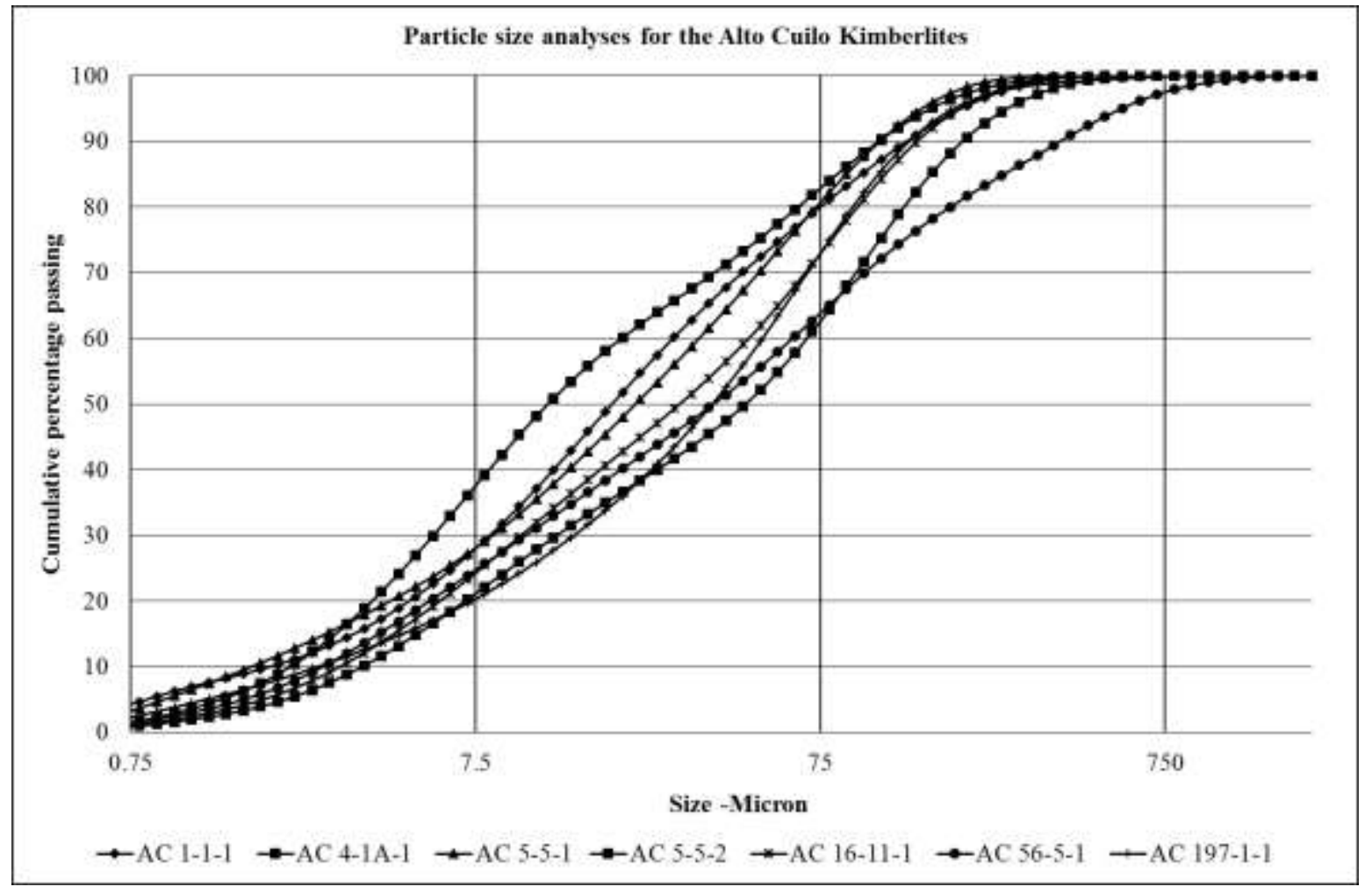

Figure 3: Particle size analysis of the Alto Cuilo kimberlites

Figure 4 shows the particle size analyses of Itengo/Tchegi kimberlites. Sample particles size distributions range between $20 \%$ and $40 \%$ passing $7.5 \mu \mathrm{m}$, and $80 \%$ and $95 \%$ passing $75 \mu \mathrm{m}$, except with AO 323 where $70 \%$ of the particles are passing $75 \mu \mathrm{m}$. This size range is known to be colloidally stable. 


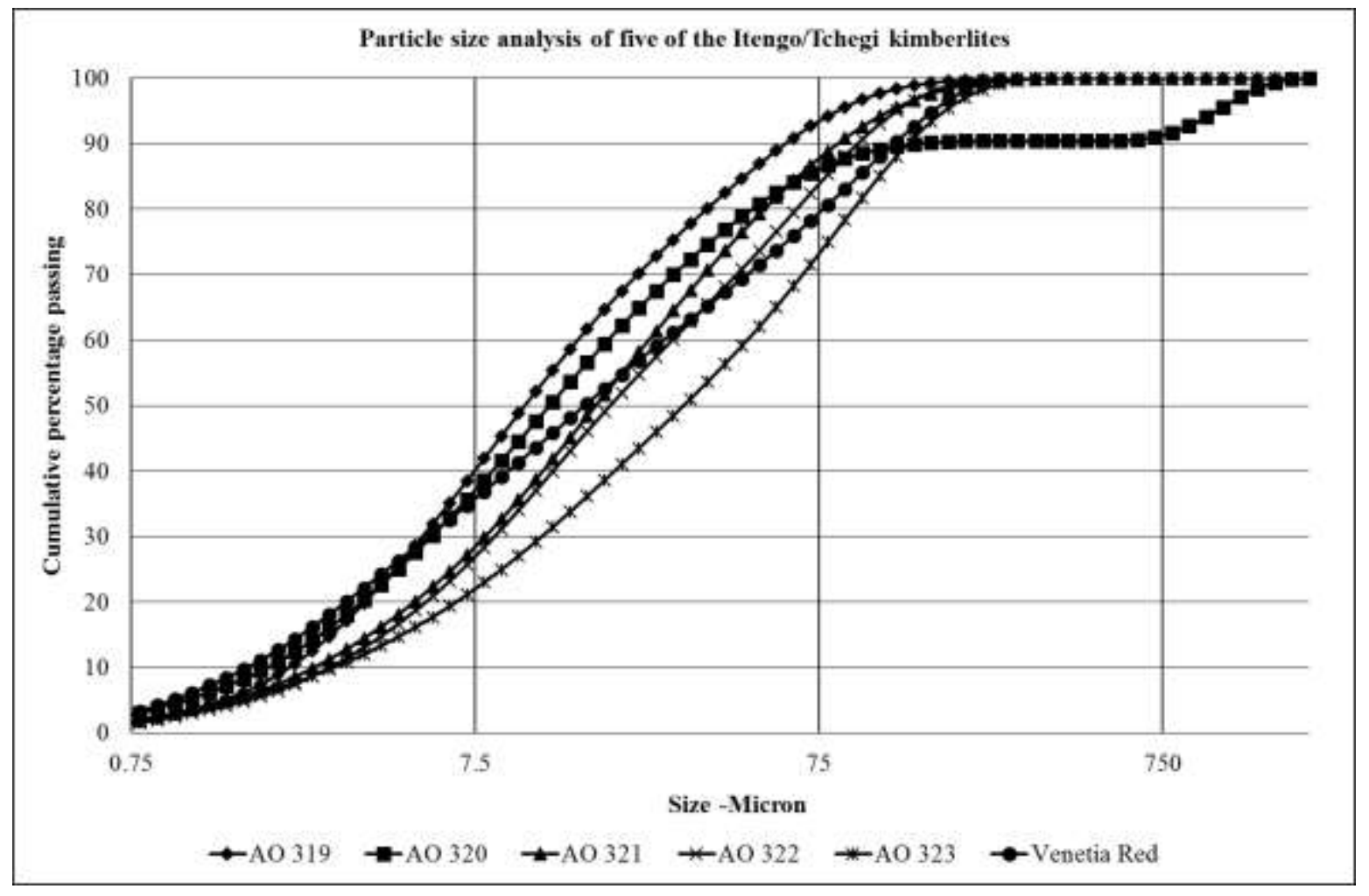

Figure 4: Particle size analysis of five of the Itengo/Tchegi kimberlites

Figure 5 shows the particle size analyses of 5 Itengo/Tchegi kimberlites compared to Venetia Red. Sample particles size distributions range between $20 \%$ and $40 \%$ of the particles passing $7.5 \mu \mathrm{m}$. All the samples have at least $80 \%$ of the sample particles smaller than $75 \mu \mathrm{m}$, while AO 327 and AO 328 have a size range where more than $90 \%$ are smaller than $75 \mu \mathrm{m}$. This could be indicative of softer kimberlites which break down more easily and could lead to a slower settling rate because of the finer particles. 


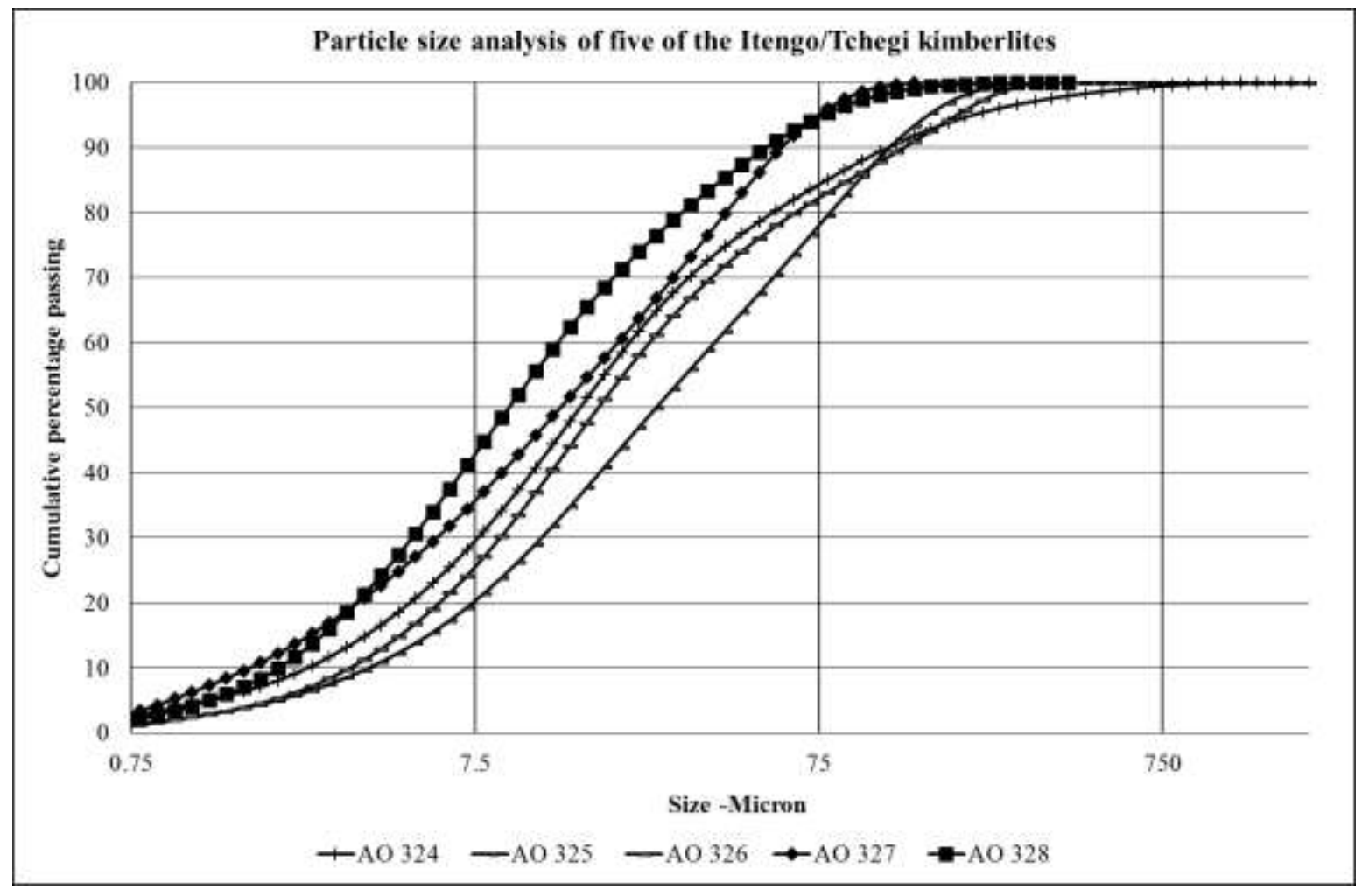

Figure 5: Particle size analysis of five of the Itengo/Tchegi kimberlites and Venetia Red

\subsection{Natural settling}

Two kimberlites, namely AC 1-1-1 and AC 5-5-1, settled out naturally, while the other 16 kimberlites experienced colloidal stability.

\subsection{1 $\mathrm{pH}$ of the kimberlite slurry solutions}

The $\mathrm{pH}$ value of all the kimberlite slurries tested was within the colloidal stable range of between 9 and 11, regardless of the amount of smectite a kimberlite contained, as shown in Figure 6. The $\mathrm{pH}$ values are thus above the point of zero charge, leading to $\mathrm{OH}^{-}$ions dominating the surface charge. The $\mathrm{pH}$ values of the slurries fall within the $\mathrm{pH}$ range of 
between 9 and 11, which are required for colloidal stability to exist, according to Vietti's (2004) model. The outstanding requirement according to the model is an ESP of more than $15 \%$ from a kimberlite before colloidal stability will be experienced.

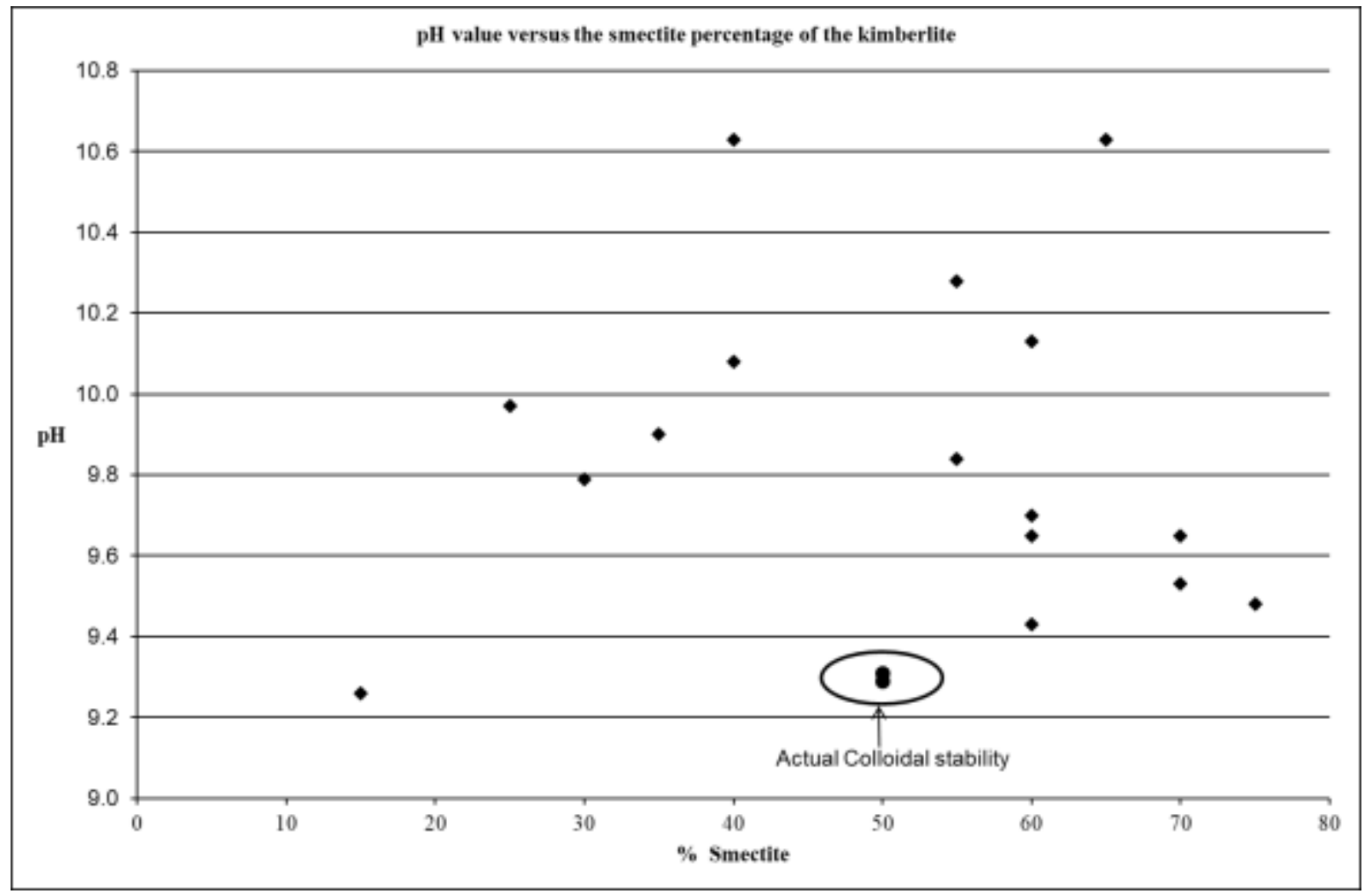

Figure 6: $\mathrm{pH}$ value of the slurry solution after 1 hour against the smectite percentage of the kimberlite

\subsubsection{Sodium exchange percentage}

Figure 7 shows the sodium exchange percentage of each kimberlite plotted against the $\mathrm{pH}$ value of the slurry. Drawn in on the graph is a line showing that to the right of the line colloidal stability is expected, and left of the line natural settling would occur according to the model of Vietti (2004). The two dots encircled on the graph represent the only two 
kimberlite samples where natural settling occurred, AC 1-1-1 and AC 5-5-1. It is very difficult to find a way to differentiate between the colloidal stable and colloidal unstable kimberlite slurries from this data.

This data does not comply with the model that Vietti (2004) proposed, where the kimberlite slimes have a colloidal stability if the exchangeable sodium percentage is higher than $15 \%$. Colloidal stability was experienced even at exchangeable sodium percentages as low as $0.7 \%$. There could still be another parameter that could be used to predict colloidal stability of a kimberlite slurry if the pH of the slurry is between 9 and 11 .

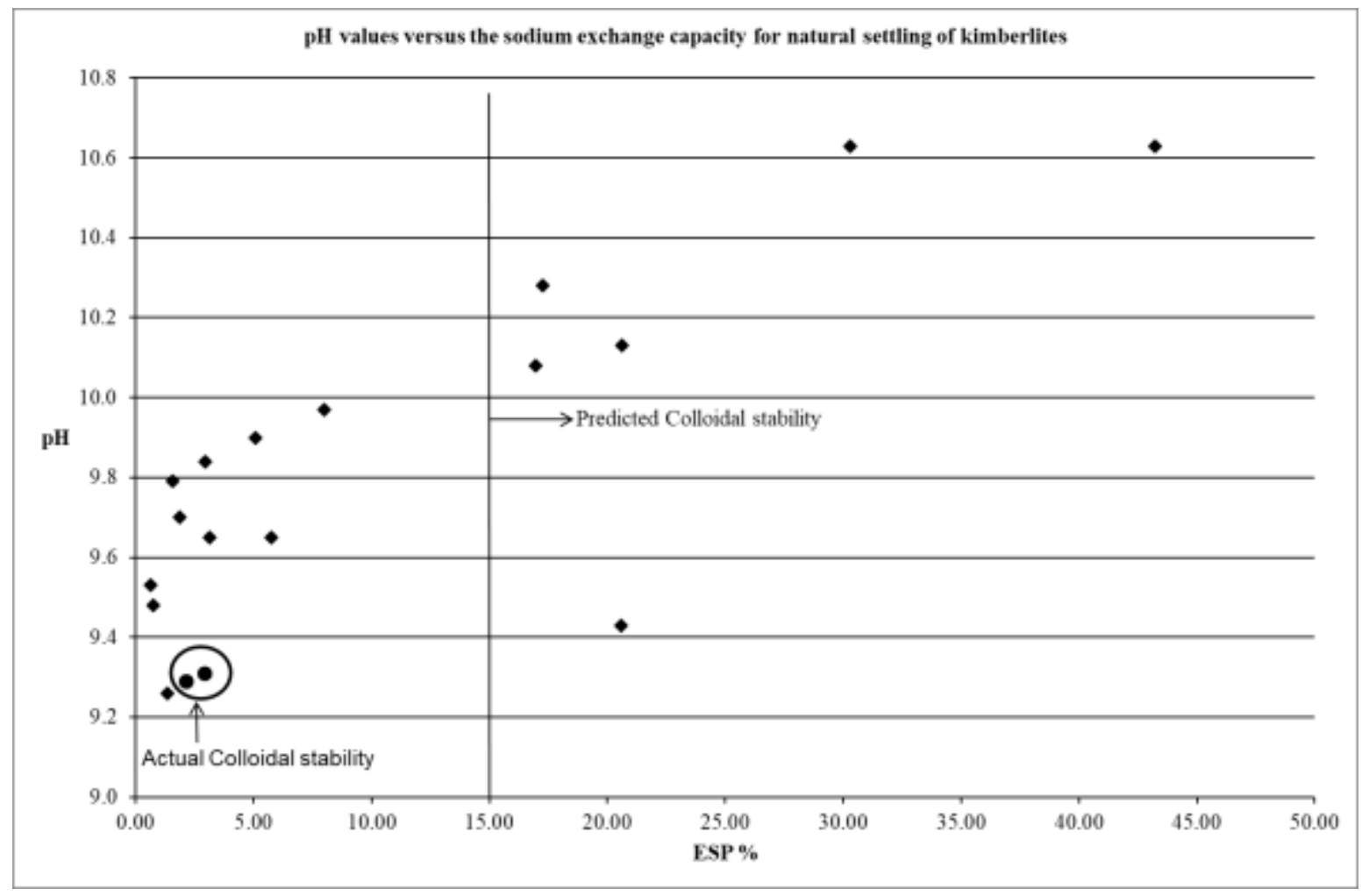

Figure 7: $\mathrm{pH}$ values of the slurries plotted against the sodium exchange capacity of the kimberlites 


\subsubsection{Cation exchange capacity}

The cation exchange capacity of each kimberlite is plotted against the $\mathrm{pH}$ value of the slurry, as shown in Figure 8. The two kimberlites that did show colloidal instability are indicated by the two dots encircled, while all the other kimberlites experienced colloidal stability. The data on this graph allows for differentiation between colloidal stability and colloidal instability kimberlites. It could be more accurate to use the cation exchange capacity of the kimberlite along with the $\mathrm{pH}$ to predict colloidal stability.

A line is drawn in on the graph proposing that colloidal stability could be experienced when the cation exchange capacity of a kimberlite is more than $10 \mathrm{cmol} / \mathrm{kg}$ and the $\mathrm{pH}$ value of the slurry range between 9 and 11 .

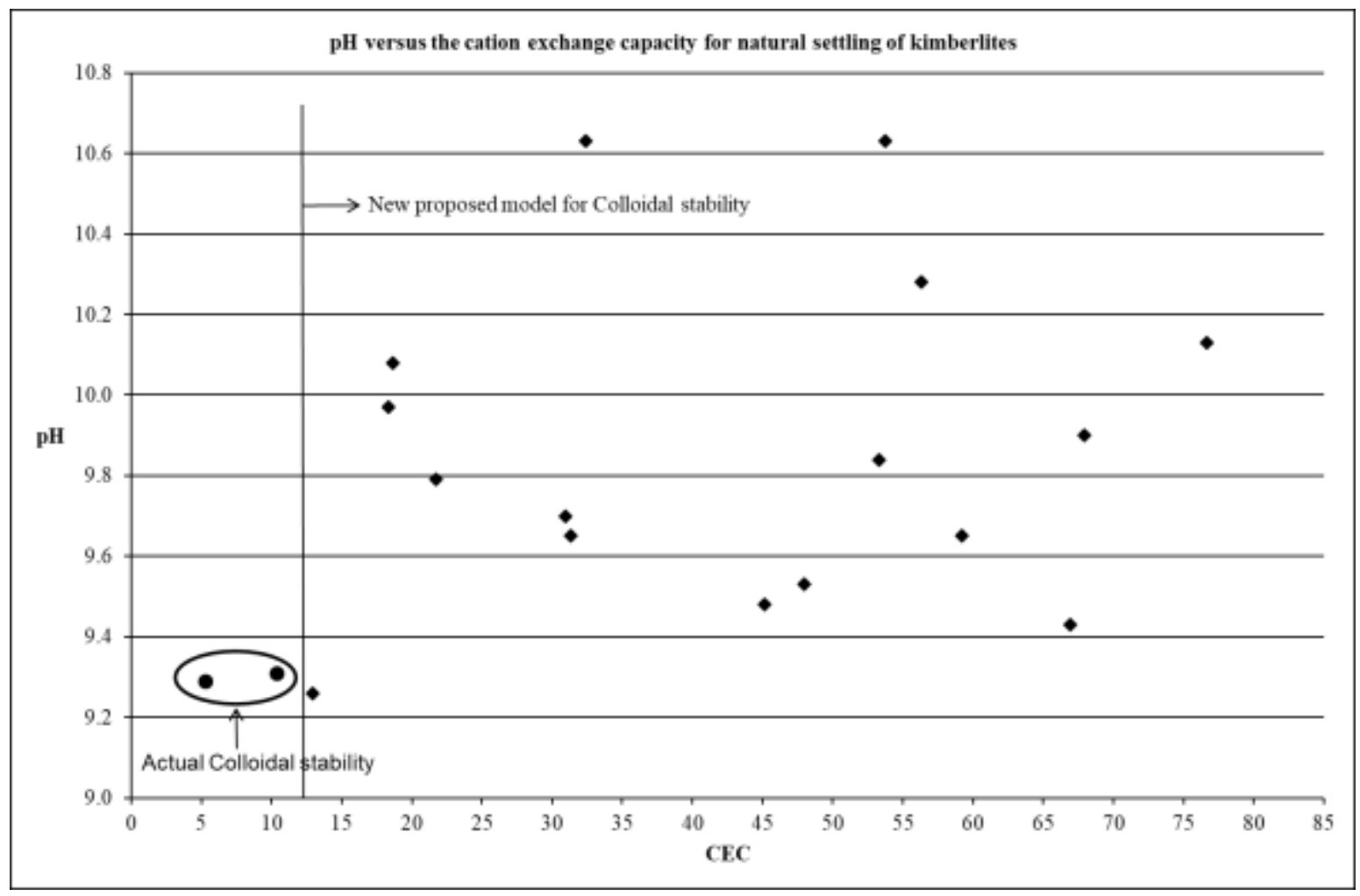

Figure 8: $\mathrm{pH}$ values of the slurries plotted against the cation exchange capacities of the kimberlites 


\subsection{Flocculant settling}

The settling rates and sediment bed weight percentages for the anionic settling of the different kimberlites are shown in Figure 9 and Figure 10. Two kimberlites, AC 56-5-1 and Venetia Red, did not settle with any of the anionic flocculants, while the remaining kimberlites had settling rates higher than the industry norm of $10 \mathrm{~m} / \mathrm{h}$ (Nguyen \& Boger, 1998). AC 16-1-1 had the lowest settling rate of $10.7 \mathrm{~m} / \mathrm{h}$, while AC 1-1-1 had the highest settling rate at $25.1 \mathrm{~m} / \mathrm{h}$. The sediment bed weight percentages ranged between $28 \%$ and $48 \%$ with an average sediment weight percentage of $35 \%$, which is significantly higher than the industry norm of between $20 \%$ and $22 \%$ weight percentage (Vietti \& Dunn, 2003). The two kimberlites that did not settle in the presence of flocculants, AC 56-5-1 and Venetia Red, both showed very high CEC and ESP values of $54 \mathrm{cmol}(+) / \mathrm{kg}$ and $30 \%$ for AC 56-5-1 and 32, and $43 \%$ for Venetia Red. It seems that the combination of CEC and ESP values could possibly allow for identification of the non-settling kimberlites. 


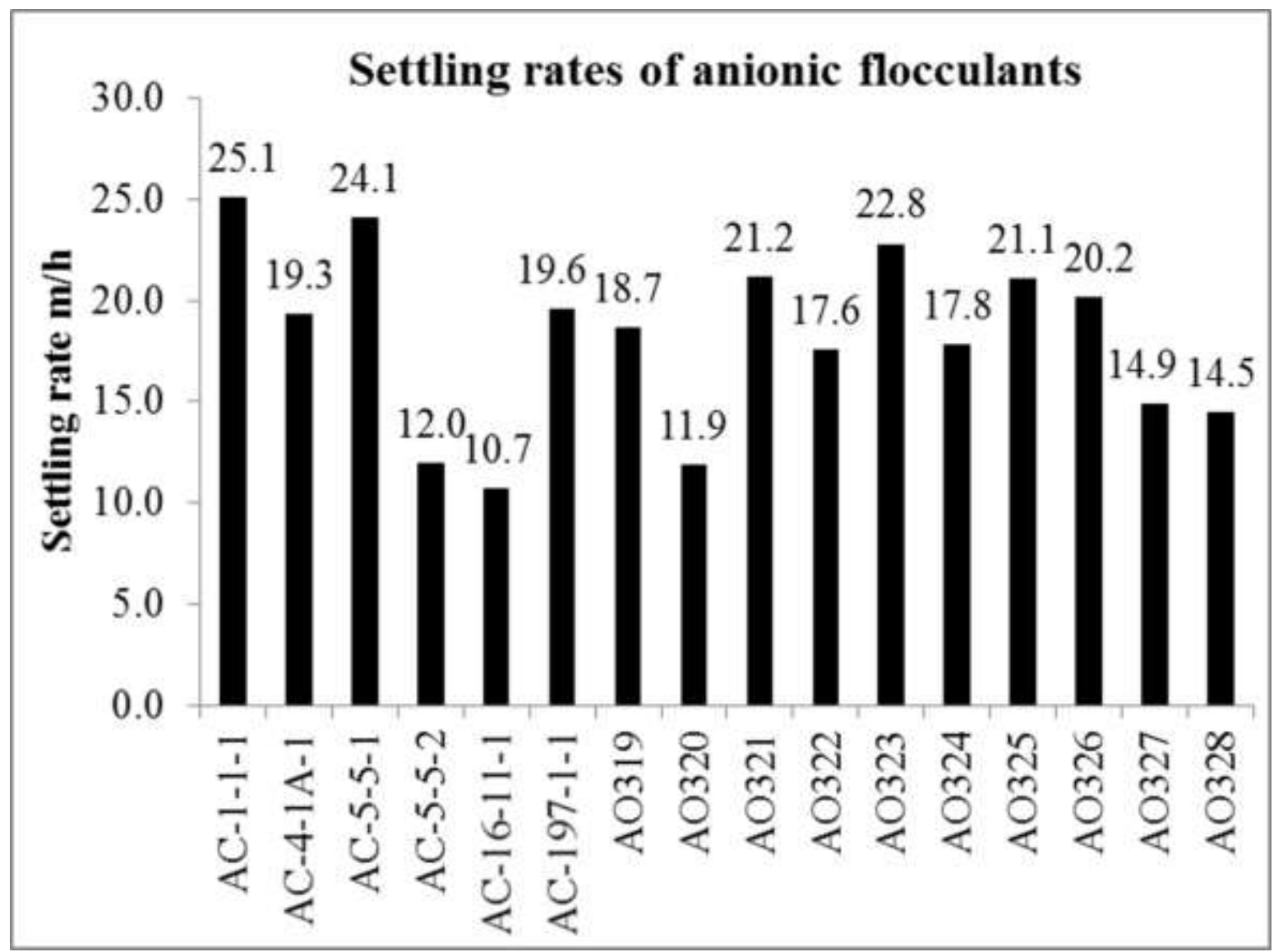

Figure 9: Settling rates of the best performing anionic flocculant for each kimberlite sample. 


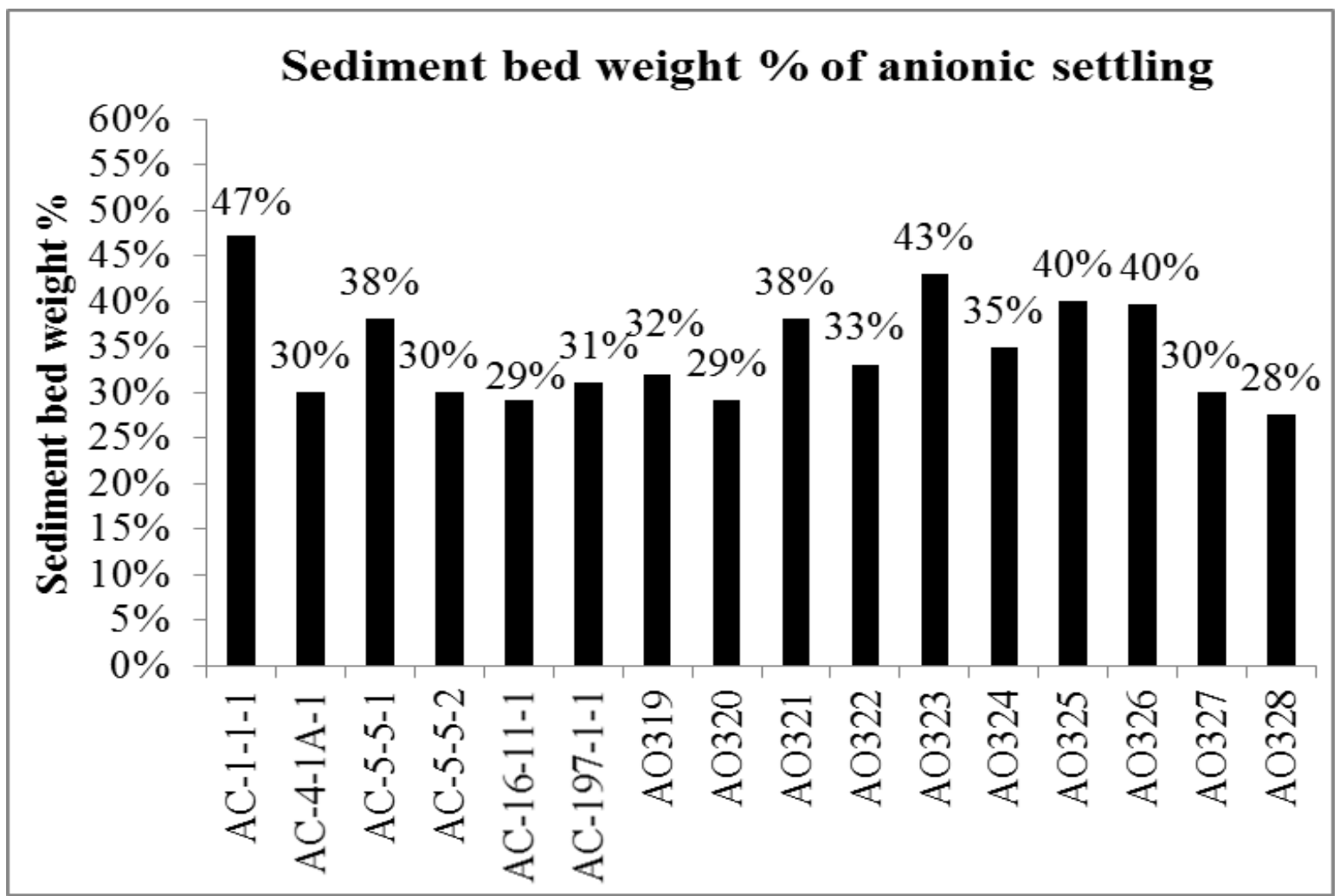

Figure 10: Sediment bed weight percentage of the best performing anionic flocculant for each kimberlite sample.

\subsection{Regression modelling}

Regression modelling was done to identify if there are any critical parameters that can predict the settling characteristics of African kimberlites with the aid of flocculants. The particle size and the $\mathrm{pH}$ of the slurry were identified as significant parameters in predicting flocculant-assisted settling with an adjusted $\mathrm{R}^{2}$ of 0.78 for the settling rate as shown in Table 2, and an adjusted $\mathrm{R}^{2}$ of 0.81 for the sediment bed depth as indicated in Table 3 . The regression fit equation for settling rate is given by: 
Flocculant settling rate $\left(\frac{m}{h}\right)=$

$-139.837 p H-91.734(7.5$ micron $)+63.416(75$ micron $)+89.52(+/-3.325)$

[1]

The regression fit equation for the sediment bed depth is given by:

Flocculant bed depth $(\%)=$

$-2.464 p H-1.571(7.5$ micron $)+1.213(75$ micron $)+1.513(+/-0.055)$

[2]

Table 2: Regression model results for flocculant settling with normalized independent variables.

\begin{tabular}{|c|c|c|c|c|c|c|c|c|c|}
\hline \multicolumn{5}{|c|}{ Flocculant settling rate - regression model -6 independent variables } & \multicolumn{5}{|c|}{ Flocculant settling rate - regression model -3 independent variables } \\
\hline R Squared & 0.838 & & & & R Squared & 0.824 & & & \\
\hline Adjusted R Squared & 0.749 & & & & Adjusted R Squared & 0.786 & & & \\
\hline Standard Error & 3.6 & & & & Standard Error & 3.325 & & & \\
\hline \multirow[t]{2}{*}{ F- Statistic } & 9.455 & & & & F - Statistic & 21.8 & & & \\
\hline & Coefficients & Standard Error & t Stat & p Value & & Coefficients & Standard Error & t Stat & p Value \\
\hline Intercept & 117.88 & 38.08 & 3.1 & 0.01 & Intercept & 89.515 & 21.161 & 4.23 & 0.0008 \\
\hline Smectite \% & -0.11 & 7.24 & -0.02 & 0.988 & $\mathrm{pH}$ & -139.837 & 27.547 & -5.076 & 0.0002 \\
\hline $\mathrm{pH}$ & -183.97 & 55.5 & -3.31 & 0.007 & 7.5 micron & -91.734 & 18.707 & -4.904 & 0.0002 \\
\hline CEC & 3.15 & 6.25 & 0.5 & 0.624 & 75 micron & 63.416 & 13.336 & 4.755 & 0.0003 \\
\hline ESP \% & 13.12 & 15.69 & 0.84 & 0.421 & & & & & \\
\hline 7.5 micron & -108.73 & 29.85 & -3.64 & 0.004 & & & & & \\
\hline 75 micron & 69.46 & 20.25 & 3.43 & 0.006 & & & & & \\
\hline
\end{tabular}

Table 3: Regression model results for flocculant bed depth with normalized independent variables.

\begin{tabular}{|c|c|c|c|c|c|c|c|c|c|}
\hline \multicolumn{5}{|c|}{ Flocculant bed depth - regression model -6 independent variables } & \multicolumn{5}{|c|}{ Flocculant bed depth-regression model -3 independent variables } \\
\hline R Squared & \begin{tabular}{|l|}
0.854 \\
\end{tabular} & & & & R Squared & \begin{tabular}{|l|}
0.846 \\
\end{tabular} & & & \\
\hline Adjusted R Squared & 0.775 & & & & Adjusted R Squared & 0.813 & & & \\
\hline Standard Error & 0.06 & & & & Standard Error & 0.055 & & & \\
\hline \multirow{2}{*}{ F - Statistic } & 10.749 & & & & F - Statistic & 25.562 & & & \\
\hline & Coefficients & Standard Error & t Stat & $\mathrm{p}$ Value & & Coefficients & Standard Error & t Stat & $\mathrm{p}$ Value \\
\hline Intercept & 1.35 & \begin{tabular}{|r|}
0.63 \\
\end{tabular} & 2.13 & 0.056 & Intercept & 1.513 & 0.348 & \begin{tabular}{|r|}
4.352 \\
\end{tabular} & \begin{tabular}{|l|l|}
2 & 0.0007 \\
\end{tabular} \\
\hline Smectite \% & 0.01 & 0.12 & 0.06 & 0.951 & $\mathrm{pH}$ & -2.464 & 0.453 & -5.444 & 0.0001 \\
\hline $\mathrm{pH}$ & -2.17 & 0.92 & -2.35 & 0.039 & 7.5 micron & -1.571 & 0.307 & -5.111 & 0.0002 \\
\hline CEC & 0.04 & 0.1 & 0.39 & 0.701 & 75 micron & 1.213 & 0.219 & 5.538 & 0.0001 \\
\hline ESP \% & -0.13 & 0.26 & -0.49 & 0.631 & & & & & \\
\hline 7.5 micron & -1.5 & 0.5 & -3.02 & 0.012 & & & & & \\
\hline 75 micron & 1.12 & 0.34 & 3.34 & 0.007 & & & & & \\
\hline
\end{tabular}




\section{Conclusion}

A single parameter could not be isolated to predict the settling behaviour of clay-rich kimberlite slimes. Colloidal stability in kimberlite slurries can be predicted by measuring the $\mathrm{pH}$ value of the slurry and determining the cation exchange capacity of the kimberlite instead of the sodium exchange percentage. If the $\mathrm{pH}$ value of a kimberlite is between 9 and 11 and the cation exchange capacity of the kimberlite is more than $10 \mathrm{cmol} / \mathrm{kg}$, colloidal stability of the slimes fraction will most probably occur. The regression data showed a correlation between $\mathrm{pH}$ and the two particle size data points, and these three values can be used as an indication of settling behaviour with the aid of anionic flocculants.

\section{References}

1. Bland, W., Rolls, D., 1998, Weathering: An introduction to the scientific principles, Arnold Publishers.

2. Chapman H.D., 1965, In Method of Soil Analysis, Part 2: Chemical and Microbiological Properties (C.A. Black), Wisconsin, p. 891-900.

3. Derjaguin, B.V., Landau, L.D, 1941, Theory of the Stability of Strongly Charged Lyophobic Sols and of the adhesion of Strongly Charged Particles in Solutions of Electrolytes, Acta Physico-chimica of the USSR 14: p.p. 633-622.

4. Klein, C., Hurlbut, CS., 1993, Manual of Mineralogy, Twenty-first Edition, John Wiley and Sons. 
5. Lagaly, G., 1993, From clay mineral crystals to colloidal clay mineral dispersions, Coagulation and Flocculation: Theory and Applications, B. Dobias (Ed), p.p.427493.

6. McFarlane, A., Bremmel, K., Addai-Mensah, J., 2005a, Microstructure, rheology and dewatering behaviour of smectite dispersions during orthokinetic flocculation, Minerals Engineering 18, p.p. 1173-1182.

7. McFarlane, A.J., Bremmel, K.E., Addai-Mensah, J., 2005b, Optimising the dewatering behaviour of clay tailings through interfacial chemistry, orthokinetic flocculation and controlled shear, Powder Technology 160, pp. 27-34.

8. Mitchell R.H., 1986, Kimberlites: Mineralogy, Geochemistry and Petrology, New York Plenum Press.

9. Mpofu, P., Addai-Mensah, J., Ralston, R., 2005, Interfacial chemistry, particle interactions and improved dewatering behaviour of smectite clay dispersions, International Journal of Mineral Processing 75, p.p. 155-171.

10. Nguyen, Q.D., Boger, D.V., 1998, Rheology to solving tailings disposal problems, International Journal of Mineral Processing 54, p.p. 217-233.

11. O' Gorman J.V. and Kitchener, J.A., 1974, The flocculation and de-watering of kimberlite clay slimes, International Journal of Minerals Processing 1, p.p. 33-49

12. Skinner E.M.W., Clement C.R., 1979, Mineralogical classification of southern African kimberlites, in Boyd FR, Meyer HOA, eds, Kimberlites, Diatremes and 
Diamonds: Their geology, petrology and Geochemistry, American Geophysical Union, Washington.

13. Svarovsky, L., 1981, Solid - Liquid separation, Second Edition, Butterworth's, London.

14. Verwey, E.J.W., Overbeek, J.T.G, 1948 Theory of the stability of Lyophobic Colloids, Elsevier Amsterdam.

15. Vietti, A.J, Know your chemistry - Suspension and Compaction behaviour of Paste. Proceedings of the International seminar on Paste and Thickened Tailings, Cape Town, South Africa, 31 March - 2 April 2004.

16. Vietti, A.J., Dunn, F., 2003, Paste and Thickened Tailings Disposal Handbook, De Beers Technical Support Services: p.p. 25-69.

17. Wills B.A., 1997, Mineral Processing Technology, 6th edition, p.p. 369-375. 